\title{
Big Data-driven Predictive Policing Innovation
}

\author{
LENG Jing ${ }^{1, \text { a }}$, Li Guojun 2* \\ ${ }^{1}$ Department of Information Technology, Hubei University of Police, Wuhan 430034, China \\ $2^{*}$ Corresponding author, Department of public security management, Hubei University of \\ Police, Wuhan 430034, China \\ aemail:daleng0127@sina.com
}

\section{Keywords: Big data; Crime prediction; Policing reform; Predictive policing}

\begin{abstract}
Traditional reactive policing encountered marginal utility difficulties in crime control, and the predictive policing driven by big data and oriented by solving problems is an important direction for future policing innovation. The big data expands the new thinking of police operation, innovates the tool of the crime prediction, and promotes multiple policing integration. Big data improves the accuracy of crime prediction, improves the effectiveness of police operation programming and develops correlation analysis and multi-angle crime control methods. Prediction policing includes the four-stage periodic working procedure including data collection, analysis, police interventions and offender behavior. It is more prominent in problem-oriented focus, rational allocation of police resources, initiative prediction of risk factors, and scientific policing operation decision.
\end{abstract}

\section{Introduction}

In recent years, big data, as a hot new technology, new thinking and new method, has become a new impetus for business innovation and government management change. The intelligence information intensive policing work is an important area of big data application. The massive data accumulated in policing work is not only a valuable data asset, but also faces the severe test of big data processing, value mining and even the change of policing operation mode. Predictive policing driven by big data and oriented by solving problems is an important direction for future policing innovation.

\section{The Development of Policing Mode from "Reaction" to "Prediction"}

The policing mode usually refers to the police department's task-specific methodological system to guide the police department's organizational form, service planning and operation control so as to respond to and resolve outstanding police issues in a certain period and region. Under the condition of limited police force preparation and fund investment, police resources will be more invested in case detection and cracking down on current crimes, focusing on explicit assessment indicators such as case detection rate, thus forming a hot focus and major case responsive police mode. Reactive policing requires shorter reaction time, higher alertness, detection rate and suspect capture rate, relying on daily law enforcement activities, responding to public requests for assistance but lacking a clear focus. In a certain period of time, the role of more police resources in a certain region for improving overall police effectiveness has been on the decline. Reactive policing is facing the marginal efficiency dilemma.

According to the theory of criminology, perpetrators and victims follow the usual life style. The characteristics of space and time affect certain patterns of crime. When committing a crime, the 
perpetrator will consider factors such as the space, the suitability of the target and the risk of being captured. Criminal behavior is predictable to some extent. Short-term micro-level crime prediction can lead the police department to deploy police intervention in a targeted manner, so as to make early warning and prevention work in advance and enhance the effectiveness of the unit's police resources.

The crime prediction based on the statistical analysis of historical crime data has been for decades, from the early manual marking analysis, the predication analysis based on the subjective experience judgment to the computer statistical analysis technique based on the mathematical model. Crime prediction technology has made great strides. The traditional crime prediction is based on low complexity and small-scale historical crime data, and the prediction is made by means of crime maps, crime hot spots analysis and comparative computer statistics. The contents of traditional crime prediction are shown in Tab.1.

Tab.1: Traditional crime prediction

\begin{tabular}{|c|c|c|c|}
\hline $\begin{array}{c}\text { Crime } \\
\text { prediction } \\
\text { content }\end{array}$ & Prediction basis & $\begin{array}{c}\text { Prediction } \\
\text { technology }\end{array}$ & Prediction target \\
\hline $\begin{array}{c}\text { Crime } \\
\text { Category }\end{array}$ & $\begin{array}{c}\text { Historical crime data, } \\
\text { report alarm } \\
\text { information data }\end{array}$ & $\begin{array}{c}\text { Crime map, statistical } \\
\text { regression analysis }\end{array}$ & Determine the hot spot of crime \\
\hline Offender & $\begin{array}{c}\text { Criminal intelligence of } \\
\text { former criminals }\end{array}$ & $\begin{array}{c}\text { Experience } \\
\text { assessment, manual } \\
\text { analysis }\end{array}$ & $\begin{array}{c}\text { Determine the connection } \\
\text { between the locations of the } \\
\text { case in a series of cases and } \\
\text { locate the possible geographical } \\
\text { location of the perpetrator }\end{array}$ \\
\hline Victim & $\begin{array}{c}\text { Domestic violence, } \\
\text { criminal intelligence of } \\
\text { violent psychiatric } \\
\text { patients }\end{array}$ & $\begin{array}{c}\text { Artificial experience } \\
\text { assessment }\end{array}$ & Rough analysis of victim risk \\
\hline
\end{tabular}

\section{Innovation Driven Transformation from "Small Data" to "Big Data"}

The emergence of big data is the result of the rapid development of information technology. Internet applications produce a lot of online data records, especially users generate unstructured data such as content, audio, text information, videos, pictures and so on. Social networks map real human social relationships in the virtual network space, and reflect the "emotional" data of people's preferences and so on. The "big" of big data is not only about its mass, but more importantly, its tremendous value. Big data is not just a technology and a tool, but also a new way of thinking. In the era of small data, random sampling, sample data and local data are replaced by the full data model in the era of big data, and the accuracy is placed in a hybrid. The statistical search, comparison, clustering, classification and other analysis of big data pay more attention to mining correlation among data variables rather than causal relationship, and can find the hidden relation network in data to form a shortcut from data to value, which has greatly changed the traditional way of thinking of exploring the laws of things and models from the causal relationship. In the era of big data, policing work confronted with a lot of ambiguous large amount of semi-structured and unstructured data, with a more emphasis on relevance rather than causal analysis, and more emphasis on real-time dynamic and static data processing. Big data-driven traditional empirical crime prediction began to change, and the "downstream response" in crime control urgently needed to be extended to "upstream prevention". "The core of the big data is the prediction." [1]Big data broadens the thinking and methods of crime prediction and changes the way traditional policing works.

Big data broadens the sources of crime prediction and crime prediction depends on real-time, and high-quality data that includes not only historical crimes, criminals, data on recent incidents, 
but also other sectors such as geographic information, transportation, meteorology, communications, staff turnover, consumption preferences and other related data. Data from different sources are processed through the necessary integration and comprehensive analysis tools are used to analyze the particularity of criminal patterns in a certain area through regression and data mining techniques. Big data-based crime prediction techniques are shown in Tab.2.

Tab.2 Crime Prediction Techniques Based on Big Data

\begin{tabular}{|c|c|}
\hline Prediction target & Prediction technology \\
\hline Crime Location / Victim & $\begin{array}{c}\text { Advanced hot spot identification models } \\
\text { Regression, classifcation, and clustering models } \\
\text { Near-repeat modeling }\end{array}$ \\
\hline Crime time & Spatiotemporal analysis methods \\
\hline Crime place & Risk terrain analysis \\
\hline
\end{tabular}

\section{Reform of Big Data Driven Predictive Policing}

In terms of the policing goal of controlling crime, a study by the National Academy of Sciences found that the effectiveness of a policing strategy in reducing crime depends on two things. On the one hand, strategies to deal with crime and disorder must be diversified and it should strengthen the relationship between police and the public so as to mobilize and integrate social forces rather than relying solely on their own law enforcement activities. On the other hand, the focus of police tactics will be more effective allocation of police resources to solve hot issues rather than indiscriminate deployment of police forces and take action. Based on these two dimensions of analysis, "standard policinng mode" has the lowest effect in reducing criminal problems, whereas "problem-oriented policing strategy" works best[2]. The SARA model of "problem-oriented policing" includes scanning, analysis, response and assessment. It emphasizes that the police should actively identify problems, focus on solving specific problems and reduce the occurrence of future problems.

Predictive policing based on big data is "the application of specialized quantitative analysis techniques to determine the goals of police intervention, crime prevention, or to explain past crimes through statistical prediction." [3]Predictive policing uses big data-based crime prediction analysis as a starting point and gives full play to the role of data in decision-making in order to enhance the rationality of police resource allocation and the effectiveness of service work. It emphasizes the prevention and intervention of crime as soon as possible before the crime has occurred, and more accurately "spotted problems" before "solving the problem" so as to achieve the transition from reaction to prevention. Predictive policing originated with a number of crime forecasting projects conducted jointly by a number of police and data technology companies. With the further development of the project and the development of big data technology, these pilot projects have promoted the new policing thinking and gradually changed the original policing operation mode.

The use of big data technology can improve the accuracy of the crime prediction and dig into the value of big data. The big data technology can improve the police service mode and improve the efficiency of the service planning. The crime is predicted by handling the data collected by the police station in time. The integration of crime analysis and police service strategy plan are used to guide the deployment of police stations, and strive to deploy appropriate police force in the right place on the right day and at the right time, so as to prevent and combat crime timely and effectively. [4] The use of big data can expand the correlation analysis and control the crime from multi angles. The big data driven predictive policing strategy has been tested in the practice of policing in many countries and has achieved good results. Predictive policing is regarded as an important way to improve the effectiveness of the police and to better promote intelligence-oriented policing and 
community policing strategies by using new technologies such as big data under the condition of a substantial increase in the number of police and budgets.

Crime prevention is inseparable from the active participation of the community and the public. It is predicted that the operation mode of policing will be basically in line with the SARA model of problem-oriented policing. Based on data analysis and sharing, the "police-community" partnership will be further improved. This has led to the integration of different policing strategies such as reactive policing, problem-oriented policing and community policing, and rational allocation of limited resources rather than mutual exclusion, and the operation mode of predictive policing is shown in Fig.1.

\section{The Innovative Ways of Predictive Policing}

First of all, it is necessary to strengthen big data thinking and promote scientific decision-making in police affairs. It is necessary to set up and strengthen the thinking of predictive policing innovation in the era of big data. The core of big data thinking is to consciously use big data technology to lead the policing work in an all-round way, optimize the allocation of policing resources, promote the scientificalness of policing decision-making, and continuously innovate policing mode and management mode. Firstly, big data thinking is full data thinking. Secondly, it should have an open thinking on cross-border thinking and correlation, actively dissolve data barriers, promote the livelihood of the police data service and the general public during the data opening up and exchange, and find out the guiding role of external social data in police work.

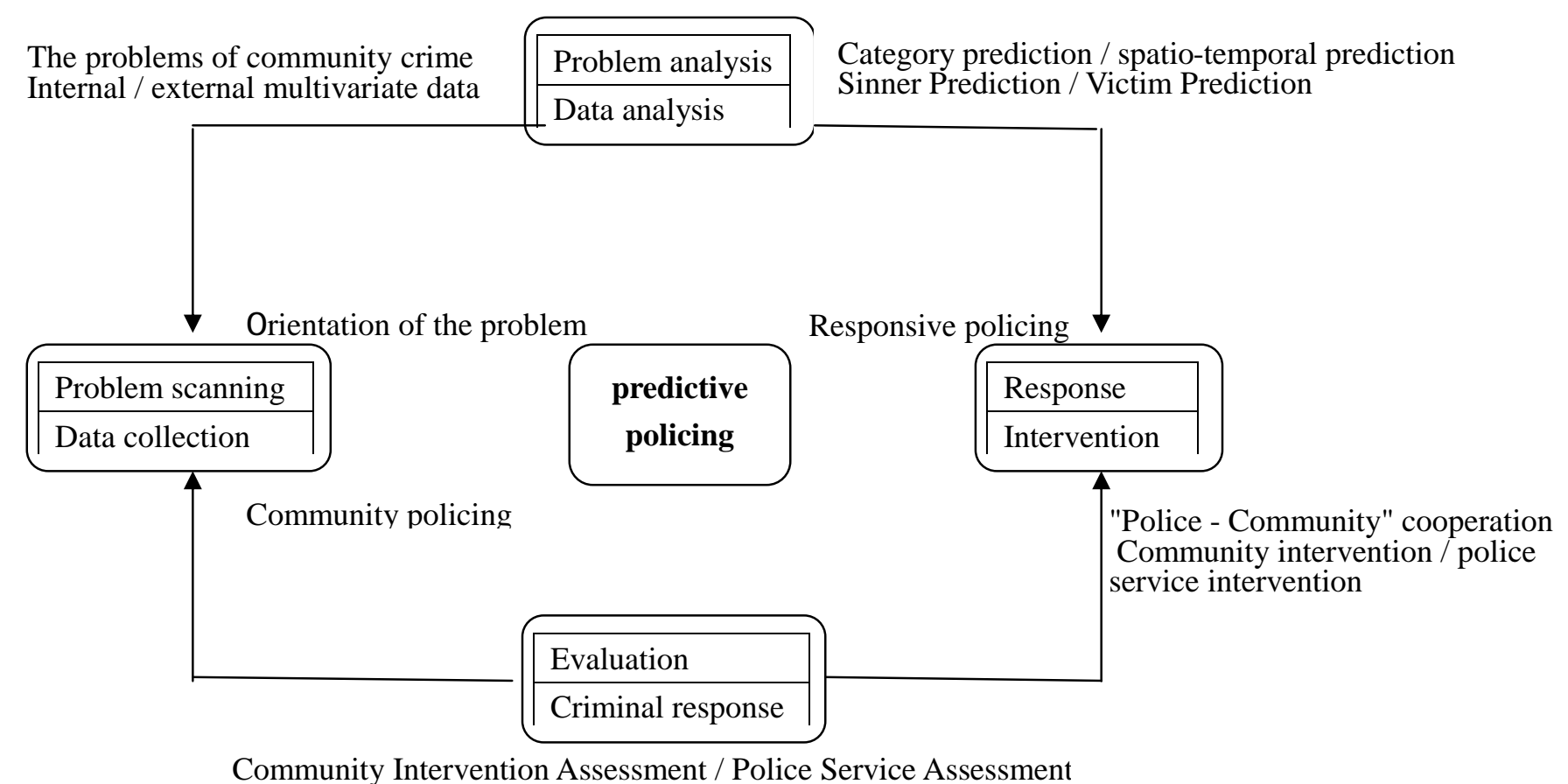

Fig.1 operation mode of predictive policing

Second, we must build a big data platform to promote the sharing of police data. From the traditional police intelligence information to big data applications, the basic data platform is the key. The collection and sharing of data with other government departments should be strengthened to promote inter-departmental data collaboration. We should also strengthen the collection and sharing of social data, continuously expand the categories and scale of data, promote data sharing, break the data barriers between regions and departments, and deepen the wider data sharing. Under the 
premise of safety, we should promote the release and sharing of police data to the public and bring into play the role of police data in public services.

Third, we must innovate big data analysis and tap the incremental value of data. The analysis and application of big data are its fundamental value. For the police data that has been accumulated for many years, the new model and analysis method can be used to re-excavate the value of the stock data. For text, image, video and other low-value-density unstructured and semi-structured big data, we should constantly innovate analytical algorithms and technical means to achieve real-time, visualization and intelligent analysis of these data.

Fourth, we must safeguard the big data to ensure the systematic use of data. Police big data applications are bound to involve more personal privacy data, so we must adhere to the data security line. We need to build a solid firewall for the storage, management and application of big data and strengthen the level of security and defense of policing big data. In terms of data usage, it is necessary to continuously improve the safety management system and strategy in big data prediction and analysis. It is necessary to break through barriers and expand the boundaries of big data sharing and development while ensuring data security and avoiding internal data corruption and external leakage. We should not only explore its value in depth, but also pay attention to protecting the privacy of citizens and avoid predictive policing falling into the ethical dilemma of encroaching upon the privacy of citizens.

\section{References}

[1]Victor Mayer - SchoenBerg, Kenneth Cukier(writer). Sheng Yangyan, Zhou Ze(translator),Big Data[M]. Hangzhou:ZheJiang People's publishing house, 2013:16

[2] Weisburd, David and John Eck. "What Can Police Do to Reduce Crime, Disorder and Fear?" The Annals of the American Academy of Political and Social Science 2004, 593(9):42-65

[3] Walter L. Perry, Brian McInnis, Carter C. Price, Susan C. Smith, John S. Hollywood.Predictive POLICING: The Role of Crime Forecasting in Law Enforcement Operations [R]. National Institute of Justice, Office of Justice Programs, U.S. Department of Justice. No. 2010-IJ-CX-K007. Rand Corporation，2013: 17-55， 1

[4] James Vlahos(writer),Zhang Yanjing(translator). Can crime be predicted, Scientific American, 2012, 2: 42-47 